\title{
Muscle fatigue and cognition: what is the link?
}

\section{Tali Kobilo and Henriette van Praag*}

Neuroplasticity and Behavior Unit, Laboratory of Neurosciences, Intramural Research Program, National Institute on Aging, Baltimore, MD, USA

*Correspondence: vanpraagh@mail.nih.gov

\section{A commentary on}

Endurance factors improve hippocampal neurogenesis and spatial memory in mice by Kobilo, T., Yuan, C., and van Praag, $H$. (2011). Learn Mem. 18, 103-107.

Increasingly, exercise is recognized as an important means to enhance cognition, improve mood, and reduce the probability of neurodegenerative diseases (Hillman et al., 2008). The beneficial effects of exercise are considered to be mediated at least in part by increased neurogenesis, elevated trophic factors, and vascularization in the hippocampus (Cotman and Berchtold, 2002; Hillman et al., 2008; van Praag, 2008). In addition, exercise has been suggested to increase the brain's resistance to oxidative stress (Radak et al., 2001).

However, high intensity exercise may have damaging central and peripheral effects. In mice, this type of exercise may result in increased brain lipid peroxidation (Rosa et al., 2007; see however Ozkaya et al., 2002; Acikgoz et al., 2006) and impaired performance in spatial learning and memory tasks (Rosa et al., 2007; Aguiar et al., 2010). In humans, high intensity exercise and overtraining (OTS) can have detrimental effects on mood. It was proposed that OTS and major depression have similar etiologies (Armstrong and VanHeest, 2002). Staleness, characterized by reduction in athletic performance and mood disturbance (O'Connor, 2007) could possibly be caused by overtraining and may be induced by changes in brain circuits involved in depression. Marathons and other forms of heavy exertion exercise may increase susceptibility to inflammatory processes during the period of training. During 1- to 2-weeks afterward muscle fatigue and stress responses are observed. Indeed, exercise concurrent with inadequate recovery, can cause performance decrements and chronic maladaptations (Appell et al., 1992; Akerström and Pedersen, 2007), such as distur- bance of the contractile apparatus of the gastrocnemius muscle. The mitochondria in skeletal muscle fibers can show focal swelling and crystalline inclusions. Cell necrosis is evident 7 days after the race (Appell et al., 1992). Furthermore, as little as 10 days of increased training may result in over-reaching (Armstrong and VanHeest, 2002).

What are the mechanisms underlying effects of overtraining on CNS? We propose that there is a strong link between factors mediating muscle endurance and brain function that may help explain the consequences of muscle fatigue on cognition. We recently demonstrated that peripheral endurance related factors lead to improved spatial memory in sedentary mice, suggesting that skeletal muscle activation by exercise or pharmacological agents underlies cognitive effects of aerobic activity (Kobilo et al., 2011; Figure 1). Our work was based on the findings that peroxisome proliferator activated receptor $\delta(\operatorname{PPAR} \delta)$ regulates muscle fiber contraction and metabolism (Wang et al., 2004; Narkar et al., 2008). PPAR $\delta$ is regulated by AMP-activated protein kinase (AMPK), a master metabolic regulator important for exercise physiology (Hardie, 2004). Treatment with AMPK agonist 5-Aminoimidazole-4-carboxamide-1$\beta$-D-ribofuranoside (AICAR) enhanced endurance in sedentary mice (Narkar et al., 2008). We showed that the effects of activation of AMPK and PPAR $\delta$ extend from the periphery to brain. AICAR had robust effects on memory, cell proliferation, and hippocampal neurogenesis, consistent with its endurance phenotype (Figure 1). The PPAR $\delta$ agonist GW501516 was less effective than AICAR reflecting its modest "exercise" phenotype (Kobilo et al., 2011). Narkar et al. (2008) showed that GW treatment increased running endurance only when it was paired with training.

Interestingly, the effects of AICAR were dependent on the duration of administration, as 7 days of treatment enhanced adult neurogenesis and memory function, but
14 days had no beneficial effects (Figure 1), and may have caused muscle fatigue. In fact, the control group showed a trend toward better performance, suggesting that long-term injection of AICAR may have bi-directional effects on cognition, similar to exercise (Akerström and Pedersen, 2007). These results are supported by finding that short-term AICAR treatment promoted sirtuin 1 protein expression in skeletal muscle, whereas 14 days did not (Suwa et al., 2011). Given the fact that intracerebral infusion of AICAR impaired memory function (Dash et al., 2006) and that AICAR has a very low ability to cross the blood brain barrier (BBB), estimated at $<1 \%$ (Marangos et al., 1990), it is likely that the beneficial effects of AICAR on the brain are indirect. Indeed, when administered peripherally, AICAR and GW may lead to release of factors from muscle into circulation that can cross the $\mathrm{BBB}$ and enhance cell genesis. Thus, similar to differential effects of moderate and high intensity exercise, AICAR improved memory and neurogenesis in a dose dependent way. Prolonged administration of AICAR may result in harmful neural responses, similar to overtraining.

We hypothesize that mechanisms contributing to muscle damage after strenuous exercise may be the same as those that could be caused by high doses of AICAR. Free oxygen radicals are generated during exercise as a side product of oxidative metabolism. In particular, increased production of nitric oxide (NO) derivates is a desired consequence of exercise for proper muscle function but higher levels of NO can cause contractile dysfunction, resulting in muscle fatigue. Strenuous exercise can accelerate the generation of $\mathrm{NO}$ to levels that result in oxidative stress (Nikolaidis et al., 2008), sustained for days after exercise (Appell et al., 1992). NO induces mitochondria biogenesis in skeletal muscle via upregulation of PGC1 $\alpha$, and interacts with AMPK. Pharmacological activation of AMPK with AICAR and the subsequent induction of GLU4 are blunted by inhibition of NO 

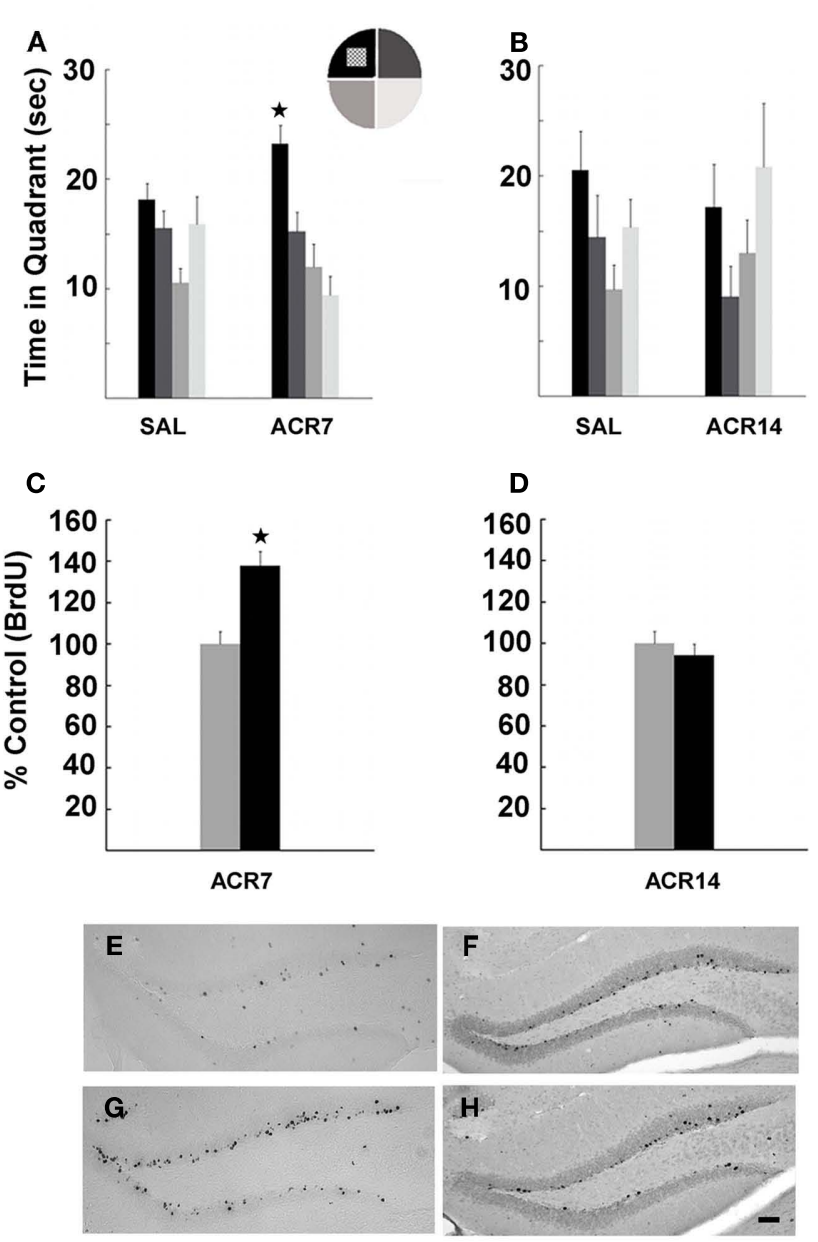

FIGURE 1 | Water maze performance and neurogenesis in mice treated with saline (SAL) or AICAR ( $500 \mathrm{mg} / \mathrm{kg}$ ) for 7 (ACR7) or 14 days (ACR14). Mice were trained to find the hidden platform in the Morris water maze over 1 week of daily training trials. The ACR7 mice performed better than SAL7 mice in probe trials. (A) Significant retention of platform location in ACR7 mice was observed $4 \mathrm{~h}\left({ }^{*} P<0.006\right)$ after the last training session. (B) ACR14 mice showed no

production. AMPK phosphorylates and activates eNOS and nNOS, and is necessary for NO-dependent increase in the expression of PGC1 $\alpha$, mitochondrial gene expression, and respiration in skeletal muscle cells. It was proposed that NO and AMPK interact through a positive feedback loop in skeletal muscle (Lira et al., 2010). Moreover, in neurons $\mathrm{NO}$ production is elicited by AMPK, and in turn, increases AMPK activity (Murphy et al., 2009). Altogether, high doses of AICAR may be harmful for body and brain. retention of spatial memory in the 4-h probe trial. In fact, the control group showed a trend toward better performance then ACR14 mice. In parallel, ACR7 significantly enhanced new cell survival (C), while there was no effect of ACR14 on BrdU+ cell number (D). Photomicrographs of BrdU ${ }^{+}$cells surviving 4 week after the last of a series of $7 \mathrm{BrdU}$ $(50 \mathrm{mg} / \mathrm{kg}$ ) and AICAR injections in SAL7 (E), ACR7 (G) mice, and SAL14 (F), ACR14 (H) mice. Scale bar, $50 \mu \mathrm{m}$.

\section{ACKNOWLEDGMENT}

This research was supported by the Intramural Research Program of the NIH of the National Institute on Aging (NIA).

\section{REFERENCES}

Acikgoz, O., Aksu, I., Topcu, A., and Kayatekin, B. M. (2006). Acute exhaustive exercise does not alter lipid peroxidation levels and antioxidant enzyme activities in rat hippocampus, prefrontal cortex and striatum. Neurosci. Lett. 406, 148-151.

Aguiar, A. S. Jr, Boemer, G., Rial, D., Cordova, F. M., Mancini, G., Walz, R., de Bem, A. F., Latini, A., Leal, R. B., Pinho, R. A., and Prediger, R. D. (2010).
High-intensity physical exercise disrupts implicit memory in mice: involvement of the striatal glutathione antioxidant system and intracellular signaling. Neuroscience 171, 1216-1227.

Akerström, T. C., and Pedersen, B. K. (2007). Strategies to enhance immune function for marathon runners: what can be done? Sports Med. 37, 416-419.

Appell, H. J., Soares, J. M., and Duarte, J. A. (1992). Exercise, muscle damage and fatigue. Sports Med. 13, 108-115.

Armstrong, L. E., and VanHeest, J. L. (2002). The unknown mechanism of the overtraining syndrome: clues from depression and psychoneuroimmunology. Sports Med. 32, 185-209.

Cotman, C. W., and Berchtold, N. C. (2002). Exercise: a behavioral intervention to enhance brain health and plasticity. Trends Neurosci. 25, 295-301.

Dash, P. K., Orsi, S. A., and Moore, A. N. (2006). Spatial memory formation and memory-enhancing effect of glucose involves activation of the tuberous sclerosis complex-mammalian target of rapamycin pathway. J. Neurosci. 26, 8048-8056.

Hardie, D. G. (2004). The AMP-activated protein kinase pathway - new players upstream and downstream. J. Cell Sci. 117, 5479-5487.

Hillman, C. H., Erickson, K. I., and Kramer, A. F. (2008). Be smart, exercise your heart: exercise effects on brain and cognition. Nat. Rev. Neurosci. 9, 58-65.

Kobilo, T., Yuan, C., and van Praag, H. (2011). Endurance factors improve hippocampal neurogenesis and spatial memory in mice. Learn. Mem. 18, 103-107.

Lira, V. A., Brown, D. L., Lira, A. K., Kavazis, A. N., Soltow, Q. A., Zeanah, E. H., and Criswell, D. S. (2010). Nitric oxide and AMPK cooperatively regulate PGC-1 in skeletal muscle cells. J. Physiol. 588, 3551-3566.

Marangos, P. J., Loftus, T., Wiesner, J., Lowe, T., Rossi, E., Browne, C. E., and Gruber, H.E. (1990). Adenosinergic modulation of homocysteine-induced seizures in mice. Epilepsia 31, 239-246.

Murphy, B. A., Fakira, K. A., Song, Z., Beuve, A., and Routh, V. H. (2009). AMP-activated protein kinase and nitric oxide regulate the glucose sensitivity of ventromedial hypothalamic glucoseinhibited neurons. Am. J. Physiol. Cell Physiol. 297, C750-C758.

Narkar, V. A., Downes, M., Yu, R. T., Embler, E., Wang, Y. X., Banayo, E., Mihaylova, M. M., Nelson, M. C., Zou, Y., Juguilon, H., Kang, H., Shaw, R. J., and Evans, R. M. (2008). AMPK and PPAR $\delta$ agonists are exercise mimetics. Cell 134, 405-415.

Nikolaidis, M. G., Jamurtas, A.Z., Paschalis, V., Fatouros, I. G., Koutedakis, Y., and Kouretas, D. (2008). The effect of muscle-damaging exercise on blood and skeletal muscle oxidative stress: magnitude and time-course considerations. Sports Med. 38, 579-606.

O'Connor, P. J. (2007). Monitoring and titrating symptoms: a science-based approach to using your brain to optimise marathon running performance. Sports Med. 37, 408-411.

Ozkaya, Y. G., Agar, A., Yargiçoglu, P., Hacioglu, G., Bilmen-Sarikçioglu, S., and Ozen, I., Alicigüzel, Y. (2002). The effect of exercise on brain antioxidant status of diabetic rats. Diabetes Metab. $28,377-384$.

Radak, Z., Sasvari, M., Nyakas, C., Kaneko, T., Tahara, S., Ohno, H., and Goto, S. (2001). Single bout of 
exercise eliminates the immobilization-induced oxidative stress in rat brain. Neurochem. Int. 39, 33-38.

Rosa, E. F., Takahashi, S., Aboulafia, J., Nouailhetas, V. L., and Oliveira, M. G. (2007). Oxidative stress induced by intense and exhaustive exercise impairs murine cognitive function. J. Neurophysiol. 98, 1820-1826.

Suwa, M., Nakano, H., Radak, Z., and Kumagai, S. (2011). Short-term adenosine monophosphate-activated protein kinase activator 5-aminoimidazole-4carboxamide-1- $\beta$-D-ribofuranoside treatment increases the sirtuin 1 protein expression in skeletal muscle. Metab. Clin. Exp. 60, 394-403.

van Praag, H. (2008). Neurogenesis and exercise: past and future directions. Neuromolecular Med. 10, 128-140.

Wang, Y. X., Zhang, C. L., Yu, R. T., Cho, H. K., Nelson, M. C., Bayuga-Ocampo, C. R, Ham, J., Kang, H., and Evans, R. M. (2004). Regulation of muscle fiber type and running endurance by PPAR $\delta$. PLoS Biol. 2, e294. doi: 10.1371/journal.pbio.0020294

Received: 13 December 2011; accepted: 20 January 2012; published online: 08 February 2012.
Citation: Kobilo T and van Praag H (2012) Muscle fatigue and cognition: what is the link? Front. Physio. 3:14. doi: 10.3389/fphys.2012.00014

This article was submitted to Frontiers in Striated Muscle Physiology, a specialty of Frontiers in Physiology.

Copyright (C) 2012 Kobilo and van Praag. This is an openaccess article distributed under the terms of the Creative Commons Attribution Non Commercial License, which permits non-commercial use, distribution, and reproduction in other forums, provided the original authors and source are credited. 